\title{
BIOLOGIA REPRODUTIVA DA LINHAGEM MERINO BOOROOLA: UM MODELO EXPERIMENTAL PARA ESTUDOS RELATIVOS Á OVULAÇÃO DOS OVNOS*
}

\author{
REPRODUCTIVE BIOLOGY OF MERINO BOOROOLA STRAIN: A EXPERIMENTAL MODEL TO \\ INVESTIGATE ASPECTS RELATED TO OWULATION IN SHEEP
}

\author{
- REVISÃO BIBLIOGRÁFICA -
}

\author{
Carlos Jose Hoff de Souza ${ }^{\star \star}$ Jose Carlos Ferrugem Moraes ${ }^{\star \star \star}$
}

RESUMO

A linhagem prolífica de ovinos Merino Booroola, e apresentada como modelo experimental para estudo da biologia da ovulação. São caracterizados o modo de herança gênica, a identificação dos genótipos, ações do gene $e$ aspectos da biologia reprodutiva para subsidiar o uso deste modelo biológico. A descrição do mecanismo de ação e o produto do gene Booroola, além de proporcionar a elucidação de aspectos do mecanismo da ovulação, poderá servir como ferramenta para o seu controle nos mamíferos.

Palavras-chave: ovinos, ovulação, Booroola, biologia reprodutiva.

\section{SUMMARY}

The prolific sheep strain Merino Booroola, is presented as an experimental model for ovulation biology studies. The heritage, genotype identification, action of the gene and also some aspects of the reproductive biology are described as a reference for further utilization of this model. The Booroola gene mechanism of action and genic product, will clear some aspects of the ovulation mechanism and can be a tool for ovulation control in mammals.

Key words: sheep, ovulation, Booroola, reproductive biology.
INTRODUÇÃO

O aumento da prolificidade via genética, por ação de um ou mais genes, apresenta como problema colateral ao aumento da taxa da ovulação, maior variância no número de produtos nascidos (NITTER, 1984). A relação fertilidade/prolificidade está subordinada ao tipo de sistema de produção aplicado, podendo ser aferida quanto à sua adequação pelo índice de mortalidade de cordeiros, sendo que um valor acima de $15 \%$ é indicativo de que a prolificidade média do rebanho em questão está elevada para o manejo de criação empregado (BRADFORD, 1985). Nas condiçōes extensivas de criação do estado do Rio Grande do Sul o incremento da prolificidade pela introdução da linhagem prolífica Merino Booroola na raça Romney Marsh, não resultou em aumento de produtividade quando aplicada de forma isolada de outras práticas de manejo, uma vez que o aumento de partos multiplos oriundos da ação deste gene principal foi acompanhado de maior mortalidade perinatal (SELAIVE-VILLAROEL et al, 1990). Não obstante, são valiosos recursos genéticos para estudo de biologia reprodutiva na espécie ovina, principalmente quanto a fatores relacionados com a ovulação (HARESIGN, 1985).

O objetivo desta revisão é de apresentar os principais aspectos da biologia reprodutiva na linhagem Merino Booroola, na qual segrega um destes genes principais de maior prolificidade.

\section{RAÇAS PROÚFICAS}

A taxa de ovulação (TO) é o critério mais adequado para avaliar a prolificidade de um rebanho, em\footnotetext{
* Parte de dissertação de mestrado, apresentada ao Curso de Pós-graduação da Faculdade de Veterinária da Universidade Federal do Rio Grande
do Sul (UFRGS).

*** Médico Veterinário, M.M.V.. Bolsista da FAPERGS, Centro Nacional de Pesquisa de Ovinos, CNPO/EMBRAPA, Caixa Postal 242, 96400-970, Bagé-RS. *** Médico Veterinário, Doutor em Genética, pesquisador do CNPO/EMBRAPA.
} 
bora a relação TO/prolificidade não seja linear, devido à maior mortalidade in utero a medida que aumenta a TO (HANRAHAN, 1980). As raças prolíficas de ovinos ou são oriundas de herança poligênica, como por exemplo nas raças Romanov e Finnsheep, ou são determinadas por um alelo de efeito principal, como os encontrados nas linhagens Merino Booroola e Romney Marsh Inverdale (DAVIS et al, 1991).

A existência destes distintos modos de ação gênica e o emprego de critérios de seleção específicos podem proporcionar respostas similares em termos de elevação na TO, como o observado por SPEAROW (1985), selecionando pelo número de crias por parto ou ganho de peso pós-aleitamento. Este fato evidencia que nem sempre serão necessariamente os mesmos genes envolvidos na determinação do número de ovulações por ciclo.

\section{GENES PRINCIPAIS}

Os genes principais determinantes de prolificidade, são promissores modelos biológicos de estudo de variação da taxa de ovulação e da ovulação propriamente dita (HARESIGN, 1985). Isto, pelo seu modo simples de herança (DAVIS et al, 1982), pela maior facilidade para introdução nas populaçc̄es (SMITH, 1985) e menor probabilidade de interação com as condições ambientais proporcionadas aos animais (MONTEGOMERY et al, 1983/1984; ISAACS et al, 1991; KLEEMAN et al, 1992). Entre os vários genes principais com atuação na taxa de ovulação e prolificidade (Tabela 1), destaca-se o gene Booroola por ser o primeiro identificado e também o mais estudado (THIMONIER et al, 1991).

Como pode ser evidenciado na Tabela 1, pelo menos sete genes principais já foram descritos em diferentes localidades. Estes genes recebem nomemclatura em função da raça/linhagem ou do local onde foram identificados pela primeira vez. É interessante salientar a possibilidade que eles tenham tido origem comum ou

Tabela 1 - Genes principais relacionados com prolificidade descritos nos ovinos.

Nome do gene

Origem

Referência

$\begin{array}{lll}\text { Booroola } & \text { Austrália } & \text { PIPER; BINDON, } 1982 \\ \text { Thoka } & \text { Islândia } & \text { JONMUNDSON;ADALTEISON,1985 } \\ \text { Javanês } & \text { Java } & \text { BRADFORD et al, 1986 } \\ \text { Cambridge } & \text { R. Unido } & \text { HANRAHAN; OWEN, 1985 } \\ \text { Criole } & \text { Martinica } & \text { MAHIEU et al, 1989 } \\ \text { Inverdale } & \text { Nova Zelândia } & \text { DAVIS et al, 1991a } \\ \text { Olkuska } & \text { Polônia } & \text { MARTYNIUK; RADOMSKA, 1991 }\end{array}$

que até mesmo sejam o mesmo gene ou alelos identificados em distintas populaçōes de ovinos. Mesmo no caso do Inverdale, que foi descrito como ligado ao cromossomo $X$, não é possível excluir esta hipótese devido a peculiaridades da evolução cariotípica na familia Bovidae, relativas a translocações X/autossomos $(B \cup N C H$, 1978; MATTHEY, 1973).

\section{MODO DE HERANÇA DO GENE BOOROOLA}

A hipótese da prolificidade da linhagem Merino Booroola, atribuída à ação de um gene principal ou grupo de genes intimamente ligados proposta por $\mathrm{Pl}$ PER \& BINDON (1982), foi confirmada por DAVIS et al (1982) em rebanhos Merino. Nesta oportunidade foi demonstrado um modo de herança simples, onde 0 alelo favorável foi denominado " $F$ " e o tipo selvagem "+". Ratificada, também, quando da introgressão deste gene em rebanhos Romney Marsh (DAVIS \& KELLY, 1983). Atualmente a denominação dos genes principais que afetam a prolificidade e taxa de ovulação em ovinos foi padronizada. Este gene passou a ser chamado de Booroola ou $\mathrm{Fec} e$ os alelos, $\mathrm{Fec}^{\mathrm{B}}$ para o favorável e $\mathrm{Fec}^{+}$ para o selvagem (COGNOSAG, 1989).

\section{IDENTIFICAÇÃO DO GENÓTIPO DAS FÊMEAS}

Em rebanhos onde segrega o gene $\mathrm{Fec}$, os genótipos são identificados com base na TO, tanto em ovulação espontânea quanto induzida por gonadotrofinas (DAVIS et al, 1982; DRIANCOURT et al, 1990; THOMAS et al, 1991). As ovelhas são consideradas $\mathrm{Fec}^{\mathrm{B}} \mathrm{Fec}^{\mathrm{B}}$ quando a TO for igual ou superior a $5, \mathrm{Fec}^{\mathrm{B}} \mathrm{Fec}^{+} \mathrm{com}$ TO entre 3 e $4 \mathrm{e} \mathrm{Fec}^{+} \mathrm{Fec}^{+}$com TO máxima de 2 (DAVIS et al, 1982). Entretanto esse critério é questionável em função de TO de população base onde o gene está segregando, pela possibilidade de outros loci influenciar a ação do gene principal e a sua penetrância. Para obtenção de uma maior precisão na identificação genotípica há necessidade de repetidas mensurações de TO e/ou levar em consideração a TO da população base antes da introgressão deste gene (ELSEN et al, 1988).

Outro critério a ser utilizado para a identificação de portadores do gene $\mathrm{Fec}$ é a ocorrência de pelo menos um parto triplo durante a vida repordutiva da fêmea (DAVIS et al, 1982). 
Buscando maior rapidez na aferição dos genótipos, vários métodos foram descritos para uso em fêmeas pré-púberes, como a indução de ovulação com HCG (DRIANCOURT et al, 1990), PMSG ou extrato de hipófise (THOMAS et al, 1991). Adicionalmente, pode ser utilizada a monitoração dos perfis plasmáticos de FSH e LH a cinco semanas de vida (FERNANDEZ-ABELLA, 1985).

\section{IDENTIFICAÇÃO DO GENÓTIPO DOS MACHOS}

Pelo modo de segregação proposto para o gene Booroola, como não ligado ao sexo, este gene deveria se expressar em ambos os sexos. Entretanto, nos machos não foram identificadas diferenças no desenvolvimento e maturação do aparelho reprodutivo ou na espermatogênese que caracterizasse os diferentes genótipos (WALKER et al, 1985). Assim, a despeito da intensiva experimentação realizada não foi identificada nenhuma metodologia capaz de caracterizar, no macho, o fénotipo do gene Fec (HOCHEREU DE REVIENS \& SECK, 1991). Atualmente o genótipo dos machos é acessado pelo pedigree ou através da progênie, utilizando-se a metodologia descrita anteriormente para fêmeas.

\section{ALTERNATIVAS PARA IDENTIFICAÇÃO DO GENE FeC.}

A identificação dos genótipos pela taxa de ovulação ou pelo histórico reprodutivo é demorada e acarreta problemas de classificação errônea de genótipos. Para contornar estas dificuldades, algumas técnicas genéticas $e$ bioquímicas têm potencial para identificar 0 gene Fec, como por exemplo a busca de ligação gênica com marcadores, sondas de DNA, programas de acasalamento, clonagem em bactérias ou células de mamíferos e fusão celular (MULSANT et al, 1991). A busca de métodos para identificação do gene Fec embora intensa, não obteve sucesso até o momento, como por exemplo na evidenciação de sua ligação com fenótipos polimórficos de proteinas séricas (HENKES, 1992) ou sondas de DNA (MONTGOMERY et al, 1991; DRINKWATER et al, 1991).

\section{CARACTERIZAÇÃO DA AÇÃO DO GENE BOOROOLA}

A concentração de GnRH cerebral em áreas hipotalâmicas e extra-hipotalâmicas, são semelhantes em ovelhas Booroolas com diferentes genótipos. $O$ padrão secretório e a concentração sangüínea do GnRH no sistema porta-hipofisiário também são similares, sugerindo que a ação deste gene não se manifesta a nível hipota- lâmico (GALLE et al, 1988).

As gonadotrofinas hipofisiárias têm papel chave no desenvolvimento de folículos com mais de $2 \mathrm{~mm}$ de diâmetro, uma vez que é este o maior tamanho folicular encontrado em ovelhas hipofisectomizadas (DRIANCOURT et al, 1987). A aplicação de FSH foi capaz de induzir crescimento de folículos ovulatórios em ovelhas com supressão de gonadotrofinas pela imunização contra $\mathrm{GnRH}$, entretanto, foi demonstrado que sua atividade é dependente do padrão pulsátil de LH (MCNEILLY, 1991).

Num estudo realizado por BINDON (1984) foi observado que as ovelhas portadoras do gene $\mathrm{Fec}$, apresentam concentrações plasmáticas do FSH mais elevadas do que as não portadoras tanto na estação reprodutiva quanto no anestro. Também é atribuído ao gene Booroola um aumento da amplitude no pulso de $\mathrm{LH}$ e maior volume e concentração de $\mathrm{FSH}$ no tecido hipofisiário embora os níveis de LH não sejam alterados (MCNATTY et al, 1987). Entretanto, DRIANCOURT et al (1991) estudando várias raças prolíficas, incluindo a linhagem Booroola, afirmam não existir relação direta entre os níveis de $\mathrm{FSH}$ e a taxa de ovulação aferida, pela constatação de ampla variação destes parâmetros dentro de raça e entre ciclos de um mesmo indivíduo. A ação deste hormônio no âmbito ovariano sofre interferências de hormônios locais. Portanto, em decorrência destas observações, este autores concluíram, também, que nem sempre a associação de altos níveis de $\mathrm{FSH}$ com altas TO permitem atribuir ao FSH a variação na TO.

O gene Booroola provoca alterações na morfologia ovariana e na foliculogênese. A população de folículos cavitários e a proporção de folículos não atrésicos na fase folicular são semelhantes independentemente do genótipo, enquanto que os folículos pré-ovulatórios das $\mathrm{Fec}^{\mathrm{B}} \mathrm{Fec}^{+}$apresentam menor diamêtro quando comparados com folículos de fêmeas $\mathrm{Fec}^{+} \mathrm{Fec}^{+}$, em igual estágio de maturação (MCNATTY et al, 1985). O diâmetro médio de folículos pré-ovulatórios e o número médio de células da granulosa segundo MCNATTY et al (1986) estão descrito na Tabela 2. Esta tabela contém dois tipos de informaçōes interessantes ligadas ao possível modo de ação do gene Fec. Primeiro, caracteriza a magnitude das diferenças de tamanho médio dos folículos nos diferentes genótipos e, secundariamente, permite inferir que o número total de células da granulosa nos folículos secretores de estrógeno/animal são similares entre os genótipos devido a variação no número de folículos pré-ovulatórios em cada genótipo. Na secreção de esteróides ovarianos, androstenediona, testosterona e estradiol também ocorre fenômeno semelhante, demonstrando que a despeito da marcada diferença na morfologia ovariana, o hipotálamo e a hipófise são expostos a semelhante ambiente de esteróides nos diferentes genótipos do gene Fec (MCNATTY et al, 1987).

A produção e a secreção de inibina tem apre- 
Tabela 2 - Caracteristicas de folículos pré-ovulatórios de acordo com o genótipo quanto ao gene Booroola

\section{Genótipo Diâmetro(mm) Céls. granulosa $\left(x 10^{6}\right)$}

$\begin{array}{lll}\mathrm{Fec}^{\mathrm{B}} \mathrm{Fec}^{\mathrm{B}} & 3,4 \pm 0,3 & 1,8 \pm 0,3 \\ \mathrm{Fec}^{\mathrm{B}} \mathrm{Fec}^{+} & 4,1 \pm 0,2 & 2,2 \pm 0,3 \\ \mathrm{Fec}^{+} \mathrm{Fec}^{+} & 6,8 \pm 0,3 & 6,6 \pm 0,3\end{array}$

Adaptado de MCNATTY et al (1986)

sentado resultados contraditórios quanto à ação de gene Booroola, sendo relatado nas portadoras menor concentração de inibina no tecido ovariano (CUMMINS et al, 1983), maior concentração plasmática na veia ovárica $48 \mathrm{~h}$ após a luteólise (TSONIS, 1988) e menores concentrações plasmáticas periféricas durante todo ciclo estral (MCNATTY et al, 1991). A produção in vitro de inibina em amostras padronizadas de células da granulosa foi semelhante entre os genótipos do gene Fec (HENDERSON et al, 1991), entretanto, em cultivos in vitro de folículos em estágios similares de maturação, provenientes de ovelhas com diferentes genótipos, a produção de inibina foi menor nas $\mathrm{Fec}^{\mathrm{B}} \mathrm{Fec}^{+}$. Contudo esta característica não é prerrogativa das portadoras do gene Booroola uma vez que outras raças prolíficas, Romanov e Finnsheep, comportaram-se da mesma maneira (DRIANCOURT et al, 1991).

O fluxo sangüíneo capilar de folículos não atrésicos é maior nas ovelhas portadoras do gene $\mathrm{Fec}$, conseqüentemente estes recebem maior aporte de nutrientes e gonadotrofinas, justificando a maturidade e capacidade de ovulação em etapas precoces da foliculogênese nesta linhagem prolifica (BROWN et al, 1991). Adicionalmente, folículos provenientes de ovelhas $\mathrm{Fec}^{\mathrm{B}} \mathrm{Fec}^{+}$quando cultivados in vitro apresentam um padrão de secreção de proteínas diferentes do observado em não portadoras. Esta diferença concentra-se em proteínas de $30 \mathrm{KD}$, podendo estar relacionadas com fatores angiogênicos de mesmo peso molecular, e que também foram identificados no fluido folicular. As caracteristicas de migração destas proteínas, indiçam que são glicosiladas e que não se constituem sub-unidades de uma molécula maior, podendo neste grupo de proteínas estar ou ser o produto gênico do gene Booroola (DRIANCOURT, 1991).

\section{BIOLOGIA REPRODUTIVA DO GENE FeC}

A idade à puberdade é fortemente influenciado pelo ambiente, refletindo a importância da nutrição e a relação peso corporal/primeiro cio. Em condições extensivas a apresentação de cio no primeiro ano de vida é inferior a $10 \%$, não sendo influenciada pelo gene Fec. Da mesma forma, neste estudo que comparou diferentes linhagens de Merino, inclusive a Booroola, a idade média à puberdade foi similar, quando ajustada pela idade da mãe, tipo de parto, peso vivo ao desmame e aos 18 meses, sugerindo que o gene Fec também não influencia esta caracteristica (BINDON et al, 1982). Em cordeiras Booroola $x$ Merino d'Arles nascidas no outono, 0 genótipo também não influenciou na idade à primeira ovulação, indicando que à ação do gene Booroola não é importante, talvez variando de acordo com a raça em que se encontre presente (FERNANDEZ-ABELLA, 1985).

As ovelhas da linhagem Booroola quando comparadas com as de linhagens Merino năo prolíficas, apresentaram uma duração da estação reprodutiva $40 \%$ superiror, com $60 \%$ das fêmeas ovulando durante todo 0 ano. Entretanto, qualquer inferência sobre o efeito do gene Fec na estacionalidade fica comprometida pela não identificação dos genótipos neste estudo (BINDON et al, 1982).

Nas ovelhas da linhagem Booroola, a duração da manifestação de estro é semelhante à observada em linhagens não prolíficas de Merino, apresentando duração média de 29h (BINDON et al, 1982), contrastando com o comportamento de outras raças prolíficas que apresentam estro prolongado (HANHARAN \& QUIRKE, 1975).

A taxa de ovulação média nas ovelhas Booroola é de respectivamente 4,$26 ; 2,95$ e 1,46 para os genótipos $\mathrm{Fec}^{\mathrm{B}} \mathrm{Fec}^{\mathrm{B}}$, $\mathrm{Fec}^{\mathrm{B}} \mathrm{Fec}^{+}$e $\mathrm{Fec}^{+} \mathrm{Fec}^{+}$(DAVIS et al, 1984). Esta característica além do genótipo é também influenciado pela estacionalidade onde o nivel de ovulação da primavera representa aproximadamente $70 \%$ do observado no outono (FERNANDEZ-ABELLA et al, 1986). Outros fatores importantes são $O$ nível nutricional (MONTGOMERY et al, 1985) e a administração de até $700 \mathrm{Ul}$ de PMSG (KELLY et al, 1983/1984), sendo que ambos têm efeito aditivo sobre a TO, embora mantendo a diferença entre os genótipos.

O estudo realizado por BINDON et al (1982), avaliando o intervalo entre ovulações na linhagem Booroola, incluiu apenas ovelhas com TO igual ou superior a 4, portanto, pelo menos portadoras do gene $\mathrm{Fec}^{\mathrm{B}}$, constatou que este intervalo não foi superior a quatro horas. No entanto, este estudo não considerou a diferença entre os genótipos.

CUMMING et al (1973), demonstraram que em ovelhas ciclando naturalmente, o pico de LH (hormônio luteinizante) pré-ovulatório, ocorre síncrono com o início da manifestação de estro, embora com uma variação de até 9 horas entre ambos. Esses autores afirmam ainda que 0 intervalo entre $c$ pico de $\mathrm{LH}$ e a ovulação $\theta$ constante, sendo de 23-25 horas tanto em ovulação natural quanto induzida. Entretanto, LAND et al, (1973) pro- 
põem que o intervalo entre $o$ início do estro e o pico de LH está relacionado com o número de ovulações, considerando estudos realizados em diferentes raças (Tabela 3), exceto com relação aos Merino Booroola.

Tabela 3 - Taxa de ovulação e intervalo entre estro e pico de LH pré-ovulatório em ovelhas de baixa e alta prolificidade.

\begin{tabular}{|c|c|c|c|}
\hline $\begin{array}{l}\text { Grupo } \\
\text { racial }\end{array}$ & $\begin{array}{l}\text { Taxa de } \\
\text { ovulação }\end{array}$ & $\begin{array}{c}\text { intervalo } \\
\text { estro/pico } \\
L H(h)\end{array}$ & Referência \\
\hline $\begin{array}{l}\text { Romanov } \\
\text { Berrichon } \\
\text { Solognote }\end{array}$ & $\begin{array}{l}2,6 \\
1,1 \\
1,1\end{array}$ & $\begin{array}{r}17,6 \\
6,0 \\
8,0\end{array}$ & $\begin{array}{l}\text { LAND et al } \\
(1973\end{array}$ \\
\hline $\begin{array}{l}\text { Romanov } \\
\text { lle-de-France }\end{array}$ & $\begin{array}{l}2,7 \\
1,6\end{array}$ & $\begin{array}{r}20,3 \\
5,0\end{array}$ & $\begin{array}{l}\text { BINDON et al } \\
(1979)\end{array}$ \\
\hline $\begin{array}{l}\text { Romanov } \\
\text { lle-de-France }\end{array}$ & $\begin{array}{l}3,2 \\
1,5\end{array}$ & $\begin{array}{r}20,0 \\
6,0\end{array}$ & $\begin{array}{l}\text { CAHILL, et al } \\
(1981)\end{array}$ \\
\hline $\begin{array}{l}\text { Finnsheep } \\
\text { Suffolk }\end{array}$ & $\begin{array}{l}3,2 \\
1,5\end{array}$ & $\begin{array}{l}9,9 \\
1,4\end{array}$ & $\begin{array}{l}\text { WHEATON et al } \\
(1977)\end{array}$ \\
\hline $\begin{array}{l}\text { Finnsheep } \\
\text { Galway }\end{array}$ & $\begin{array}{l}3,6 \\
1,6\end{array}$ & $\begin{array}{l}8,9 \\
-0,6\end{array}$ & $\begin{array}{l}\text { QUIRKE et al } \\
\text { (1979) }\end{array}$ \\
\hline $\begin{array}{l}\text { Booroola } \\
\text { Merino }\end{array}$ & $\begin{array}{l}2,7 \\
1,3\end{array}$ & $\begin{array}{l}4,4 \\
4,8\end{array}$ & $\begin{array}{l}\text { BINDON et al } \\
(1978)\end{array}$ \\
\hline
\end{tabular}

^ = ovelhas prolificas; adaptado de BINDON (1984).

BINDON et al (1984), embora sem considerar a segregação do gene $\mathrm{Fec}$, confirmaram o comportamento dos Booroola semelhante ao das raças não prolíficas de ovinos, quanto ao intervalo estro/pico de LH. Em contraste, estes autores afirmam a ocorrência de antecipação da ovulação em relação à descarga de LH pré-ovulatória, contrariando o postulado de CUMMING et al (1973) para a espécie ovina.

A despeito do grande número de estudos sobre a taxa de ovulação nos Merino Booroola, pouco se sabe sobre a dinâmica ovulatória e o momento da ovulação nos diferentes genótipos desta linhagem. Num mesmo grupo racial não foi observada diferença na dinâmica ovulatória após o início do cio espontâneo, nem após a indução da ovulação com gonadotrofinas durante 0 anestro estacional. Mesmo assim, não pode ser descartada a hipótese de comportamento peculiar quanto a resposta ao pico de $\mathrm{LH}$, pelo fato que este hormônio não foi aferido (SOUZA, 1993).

\section{CONCLUSÃO}

Entre os genes de efeito principal sobre a TO,
- denominado Fec, apresenta herança autossômica simples promovendo variações na morfologia ovariana e fisiologia folicular, que resultam em maiores taxas de ovulação. Existem ainda aspectos obscuros quanto à precisão na identificação genotípica, pelo desconhecimento do produto gênico de $\mathrm{Fec}$ e seu real mecanismo de ação. Em decorrência das peculiaridades identificadas, o desenvolvimento de estudos relativos a biologia reprodutiva empregando estes indivíduos como modelo experimental, certamente contribuirão para uma melhor compreensão do mecanismo da ovulação. Adicionalmente, após a identificação do gene Fec estará disponivel o conhecimento para o controle da ovulação nos mamíferos.

\section{REFERÊNCIAS BIBLIOGRÁFICAS}

BINDON, B.M. Reproductive biology of the Merino Booroola Sheep. Australian Journal of Biological Sciences Melbourne, v. 37, p. 163-89, 1984.

BINDON, B.M., BLANC, M.R., PELLETIER, J., et al. Peri-ovulatory gonadotrophin and ovarian steroid patterns in sheep of breeds with differing fecundity. Journal of Reproduction and Fertility, Oxford, v. 55, p. 15-25, 1979.

BINDON, B.M., PIPER, L.R., THIMONIER, J. Preovulatory $\mathrm{LH}$ characteristics and time of ovulation in the prolific Booroola Merino ewe. J Reprod Fert., Cambridge, v. 71, p. 519-523, 1984.

BINDON, B.M., THIMONIER, J.T., PIPER, L.R. Timming of the preovulatory $\mathrm{LH}$ discharge in high fecundity sheep. Proceedings of the Australian Society of Reproductive Biology, v. 10, p. 82, 1978.

BINDON, M.L., PIPER, L.R., EVANS, R. Reproductive biology of the Booroola Merino. In: INTERNATIONAL WORKSHOP ARMINDALE, 1980, Australia. The Booroola Merino. Armindale, Australia, CSIRO, 1982, p. 21-34. $96 \mathrm{p}$.

BRADFORD, G.E. Selection for litter size. In: LAND, R.B., ROBINSON, D.W. Genetics of reproduction in sheep. London: Butterworths, 1985, p. 3-18.

BRADFORD, G.E., QUIRKE, J.F., SITORUS, P., et al. Reproduction in Javanese sheep: Evidence for a gene with large affect on ovulation rate and litter size. $J$ Anim Sci, Champaing, v. 63, p. 418-431, 1986.

BROWN, B.W., MATTNER, P.E., BINDON, B.M. Capillary blood flow in ovarian follicles and corpora lutea in Booroola and control Merino ewes. In: INTERNATIONAL WORKSHOP TOLOUSE, 1990, France. Major genes for reproduction in sheep. Tolouse, France, INRA, 1991, p. 135-144. 457 p.

BUNCH, T.D. Fundamental Karyotype in domestic and wild species of sheep. The Journal of Heredity, v. 69, p. 77-80, 1978. 
CAHILL, L.P., SAUMANDE, J., RAVAULT, J.P., et al. Hormonal and follicular relationships in ewes of high and low ovulation rates. J Reprod Fert. Cambridge, v. 62, n. 1, p. 141-150, 1981.

COGNOSAG Standartised Genetic Nomenclature for Sheep and Goats (Proccedings of the 1987 Workshop), Lavoisier, Paris, 1989, p. 49-52. 72 p.

CUMMING, I.A., BUCKMASTER, J.M., BLOCKEY, M.A.B., et al. Constancy of interval between luteinizing hormons release and ovulation in the ewe. Biology of Reproduction Boston, v. 9, p. 24-9, 1973.

CUMMINS, L.J., O'SHEA, T., VINDON, B.M., et al. Ovarian inhibin content and sensivity to inhibin in Booroola and control Merino ewes. J Reprod Fert, Cambridge, v. 67, n. 1, p. 1-7, 1983.

DAVIS, G.H., ARMSTRONG, J.R., ALLISON, A.J. Ovulation rates and litter sizes of Booroola ewes classified homozygous, heterozygous and non carrier for the Booroola gene and the transfer of the Booroola gene from the Merino into another breed. Proceedings of $2^{\text {nd }}$ World Congress on Sheep and Beef Cattle Breeding. Pretoria, 1984, p. 16-19.

DAVIS, G.H., KELLY, R.W. Segregation of a major gene influencing ovulation rate in progeny of Booroola sheep in commercial and research flocks. Proceedings N.Z. Soc Anim Prod, v. 43, p. 197-199, 1983.

DAVIS, G.H., MCEWABM H.C., FENNESSY, P.F., et al. Evidence for the presence of a major gene influencing ovulation rate on the $X$ chromossome of sheep. Biology of Reproduction, Champaign, v. 44, $p$ 620-624, 1991a

DAVIS, G.H., MONTGOMERY, G.M., ALLISON, A.J., et al. Segregation of a major gene influencing fecundity in progeny of Booroola sheep. N Z J Agric Res, v. 25, p. 525-529, 1982.

DAVIS, G.H., SHACKELL, G.H., KYLE, S.E. A putative major gene for prolificacy in Romney Sheep. In: INTERNATIONAL WORKSHOP TOLOUSE, 1990 France. Major genes for reproduction in sheep. Tolouse, France: INRA, 1991, p. 61-66. 457 p.

DRIANCOURT, M.A., BODIN, L., BOOMAROV, O., et al. Number of mature folicles ovulating after a challenge of human chorionic gonadotrophin in different breeds of sheep at different phisiological stages. Journal of Animal Science, Champaign, v. 69, p. 719-724, 1990.

DRIANCOURT, M.A., BODIN, L., FRY, R.C. FSH Secretion, its regulation and its relationship with ovulation rate in a range of prolific and non prolific breeds of sheep. In: INTERNATIONAL WORKSHOP TOLOUSE, 1990, France. Major genes for reproduction in sheep. Tolouse, France: INRA, 1991, p. 125-134, 457 p.

DRIANCOURT, M.A. Is the Booroola gene hidden in the ovary? In: INTERNATIONAL WORKSHOP TOLOUSE, 1990, France. Major genes for reproduction in sheөp.
Tolouse, France: INRA, 1991, p. 145-154. 457 p

DRIANCOURT, M.A., CANILL, W.R., RINDON, R.M. Ovarian follicular populations and preovulatory enlargement in Booroola and control merino ewes. $\mathbf{J}$ Reprod Fert, Cambridge, v. 73, p. 93-107, 1985.

DRIANCOURT, M.A., FRY, R.C., CLARKE, I. J., et al. Folicular growth and regression during the 8 days following hypophysectomy in sheep. $J$ Reprod Fert, $v$. 79, p. 635-642, 1987.

DRIKWATER, R.D., PIPER, L.R., BINDON, B.M., et al. Search for a Fec gene DNA marker in prolific Booroola Merino sheep. In: INTERNATIONAL WORKSHOP TOLOUSE, 1990, France. Major genes for reproduction in sheep. Tolouse, France: INRA, 1991, p. 275-280. 457 p.

ELSEN, J.M., VU TIEN KHANG, J., LE ROY, P. A statistical model for genotype determination at a major locus in a progeny test design. Génet Sel Evol, v. 20, n. 2, p. 211-226, 1988.

FERNANDEZ-ABELLA, D. Combution à l'etude endodrinienne compraree des brebis Booroola $x$ Mérinos et des Mérinos d'Arles. E.N.S.A., 1985, 54 p. Teses (doutorado em reprodução). E.N.S.A, Université de Rennes, 1985.

FERNANDEZ-ABELLA, D., BLANC, M.R., COGNIE, V. Efecto del gen 'Booroola' sobre las características reproductivas. ITEA n. 62, p. 3-22, 1986.

GALLE, J.S., SMITH, P., TRUMAN, P., et al. Immunoassay of gonatrophin-releasing hormons in brain tissue of Booroola Merino ewes. J reprod Fert, v. 82, p. $581-586,1988$.

HANRAHAN, J.P. Ovulation rate as the selection criterion for litter size in sheep. Procedings of Australian Society for Animal Production, v. 13, p. 405-408. 1980. $908 \mathrm{p}$

HANRAHAN, J.P., QUIRKE, J.F. Repeatability of the duration of oestrus and breed differences in the ralationship between duration of oestrus and ovulation rate of sheep. J Reprod Fert, v. 45, p. 29-36, 1975

HANRAHAN, J.P., OWEN, J.B. Variation and repeatability of ovulation rate in Cambridge ewes. Procedings of British Society of Animal Production, n. 38, 1985.

HARESIGN, $W$. The physiological basis for variation in ovulation rate and litter size in sheep: a review. Livestock Production Science, Amsterdam, v. 13, p. 3-20, 1985

HENDERSON, K.M., MCNATTY, K.P., WARDS, R.L., et al. Inhibin production in vitro by granulosa cells from Booroola ewes which were either homozygous or non-carriers of a fecundity gene influencing their ovulation rate. J Reprod Fert, Cambridge, v. 92, p. 147-157, 1991.

HENKES, L.E. Investigaçăo da variabilidade genética em um rebanho ovino Romney Marsh Booroola. Porto Alegre, 1992, 54 p. Tese (mestrado em genética). Instituto de Biociencias, Universidade Federal do Rio 
Grande do Sul, 1992.

HOCHEREAU-DE REVIERS, M.T., SECK, M. The male reproductive biology in prolific ovine breeds. In: INTERNATIONAL WORKSHOP TOLOUSE, 1990, France. Major genes for reproduction in sheep. Tolouse, France: INRA, 1991, p. 177-196. 457 p.

ISAACS, K.L., OWENS, J.L., LITTLEJOHN, R.P., et al. Influence of maternal liveweight on reproductive performanmce and wool production of heterozygous Booroola Merino $x$ Coopworth $\left(\mathrm{Fec}^{\mathrm{B}} \mathrm{Fec}^{+}\right.$) and Merino $x$ Coopworth ewes. NZJ Agric Res, v. 34, p. 55-67, 1991.

JONMUNDSSON, J.V., ADALSTEINSSON, S. Single genes for fecundity in icelandic sheep. In: LAND, $R$. B., ROBINSON, D.W. Genetics of Reproduction in Sheep. London: Butterworths, 1985, p. 159-168.

KELLY, R.W., OWENS, J.L., CROSBIE, S.F., et al. Influence of Booroola Merino genotype on the responsiveness of ewes to pregnant mares serum gonadotrophin, luteal tissue weights and peripheral progesterone concentrations. Anim Reprod Sci, v. 6, p. 199-207, 1983/1984.

KLEEMANN, D. O., WALKER, S.K., WALKLEY, J.R.W., et al. Effect of premating nutrition on embryo wastage in $\mathrm{Fec}^{\mathrm{B}} \mathrm{Fec}^{+}$Booroola Merino cross ewes. In: INTERNATIONAL CONGRESS ON ANIMAL REPRODUCTION, 1992, Hague. Proceedings... The Hague, The Netherlands Congress Centre, 1992, p. 2063-2065. 2171 p.

LAND, R.B., PELLETIER, J., THIMONIER, J., et al. A quantitative study of genetic differences in the incidence of oestrus, ovulation and plasma luteinizing hormone concentration in the sheep. Journal of Endocrinology, London, v. 58, p. 305-317, 1973.

MAHIEU, M., JEGO, Y., DRIANCOURT, M.A., et al. Reproductive performances of Creole and Black-Belly ewes in the West Indies: A new major gene controlling ovulation rate? Anim Reprod Sci, Amsterdam, v. 19, p. 235-243, 1989.

MATTHEY, R. The chromosome formulae of eutherian mammals. In: CHIAREELLI, A.B., CAPANNA. E. Cytotaxonomy and Vertebrate Evolution. London: Academic Press, 1973.

MARTINIUK, E., RADOMSKA, M.J. A single gene for profilacacy in Olkuska sheep In: INTERNATIONAL WORKSHOP TOLOUSE, 1990, France. Major genes for reproduction in sheep. Tolouse, France: INRA, 1991, p. 85-92. 457 p.

MCNATTY, K.P., HENDERSON, K.M., FLEMING, J.S., et al. The physiology of the Booroola ewe. In: INTERNATIONAL WORKSHOP TOLOUSE, 1990, France. Major genes for reproduction in sheep. Tolouse, France: INRA, 1991, p. 105-124. 457 p.

MCNATTY, K.P., HUDSON, N., HENDERSON, K.M., et al. Differences in gonadotrophin concentrations and pituitary responsiveess to $\mathrm{GnRH}$ between Booroola ewes which were homozygous, heterozygous or non carriers of a major gene influencing ovulation rate. $J$ Reprod Fert, Cambridge, v. 80 , n. 2, p. 577-588, 1897.

MCNATTY, K.P., HENDERSON, K.M., LUN, S., et al. Ovarian activity in Booroola Romney ewes which have a major gene influencing their ovulation rate. $J$ Reprod Fert, Cambridge, v. 73, p. 109-1220, 1985.

MCNATTY, K.P., LUN, S., HEALTH, D.A., et al. Differences in ovarian activity between Booroola $x$ Merino ewes which were homozygous, heterozygous and non-carriers of a major gene influencing ovulation rate, J Reprod Fert, Cambridge, v. 77, p. 193-205, 1986.

MCNEILLY, A.S. The ovarian follicle and fertility. J Steroid Biochem Molec Biol, v. 40, n. 1-3, p. 29-33, 1991.

MONTGOMERY, G.W., CRAWFORD, A.M., TATE, M.L, et al. Geneticlinkage approaches to the identification of the Booroola $F$ gene. In: INTERNATIONAL WORKSHOP TOLOUSE, 1990, France. Major genes for reproductionin sheep. Tolouse, France: INRA, 1991, p. 269-274. 457 p.

MONTGOMERY, G.W., VRAY, A.R., KELLY, R.W. Ovulation rates of first cross Booroola compared with local breeds ewes following differential feeding. Animal Reproduction Science, Amsterdan, v. 6, p. 209-215, 1983/1984.

MONTEGOMERY, G.W., KELLY, R.W., DAVIS, G.H., et al. Ovulation rate and oestrus in Booroola genotypes. Some effects of age, season and nutrition. IN: LAND, R.B., ROBINSON, D.W. Genetics of Reproduction in Sheep. London: Butterworths, 1985, p. 237-244.

MULSANT, P., GELLIN, J., HATEY, F., et al. Genetical and biochemical approaches to identify and isolate the Booroola $F$ gene. In: INTERNATIONAL WORKSHOP TOLOUSE, 1990, France. Major genes for reproduction in sheep. Tolouse, France: INRA, 1991, p. 259-268. 457 p.

NITTER, G. Theoretical aspects of selection for reproductive performance, with sheep as an example. Z Tierzuchtg Zuchtgsbiol, v. 101, p. 81-95. 1984.

PIPER, L.R., BINDON, B. M. The Booroola Merino and the performance of medium non-Pepppin crosses at Armindale, in: INTERNATIONAL WORKSHOP ARMINDALE, 1980, Australia. The Booroola Merino. Armindale, Australia, CSIRO, 1982, p. 9-20. 96 p.

QUIRKE, J.P., HANRAHAN, J.P., GOSLING, J.P. Plasma progesteron levels throughout the oestrus cycle and release of $\mathrm{LH}$ at oestrus in sheep with different ovulation rates. Journal of Reproduction and Fertility, Oxford, v. 55, p. 37-44, 1979.

SELAIVE-VILLARROEL, A.B., MORAES, J.C.F., OLIVEIRA, N.M., et al. Introdução e avaliação dos efeitos de um gene determinante de prolificidade em ovinos Romney Marsh. Rev Bras Reprod Anim, Belo Horizonte, v. 14, n. 3, p. 215-221, 1990. 
SMITH, C. Utilization of major genes. In: LAND, R.B., ROBINSON, D.W. Genetics of Reproduction in Sheep. London, Butterworths, 1985, p. 151-158.

SOUZA, C.J.H. Dinâmica da ovulaçăo e biologia do cilo estral de ovelhas 3/4 Romney Marsh X 1/4 Merino Booroola portadoras ou năo de um gene principal determinante de prolificidade. Porto Alegre, 1993, 49 p. Tese (mestrado em reprodução animal). Curso de Pós-Graduação em Medicina Veterinária, Faculdade de Veterinária, Universidade Federal do Rio Grande do Sul, 1993.

SPEAROW, J.L. The mechanism of action of genes controlling reproduction. In: LAND, R.B., ROBINSON, D.W. Genetics of Reproduction in Sheep. London, Butterworths, 1985, p. 203-216.

THIMONIER, J., DAVIS, G.H., FAHMY, M.H., et al. The F gene in the world: use and research objectives. In: INTERNATIONAL WORKSHOP TOLOUSE, 1990, France. Major genes for reproduction in sheep. Tolouse, France: INRA, 1991, p. 3-14. 457 p.
THOMAS, D.L., NASH, T.G., ALI, Z., et al. Induced ovulation rate with various compounds as a criterion for determining presence or absence of the Booroola Merino $F$ gene in prepuberal ewe lambs. In: INTERNATIONAL WORKSHOP TOLOUSE, 1990, France. Major genes for reproduction in sheep. Tolouse, France: IN RA, 1991, p. 155-160. 457 p.

TSONIS, C.G., BAIRD, D.T., CAMPBELL, B.K., et al. Secretation of bioactive inhibin by the ovary of the Booroola Merino ewe with or without a copy of the fecundity (F) gene. J Endocr, v. 119, p. R5-R8, 1988.

WALKER, S.K., PONZONI, R.W., WALKLEY, J.R.W., et al. The effect of the $F$ gene on male reproductive traits in Booroola $X$ South Australian Merino rams. Anim Reprod Sci, Amsterdam, v. 9, p. 137-144, 1985.

WHEATON, J.E., RAABE, T.I., BURRILL, M.J. Characteristics of the ovulatory release of luteinizing hormone in Finn, Finn $X$ Suffolk, and Suffolk ewes. J Endocrinol, v. 75, p. $449-450,1977$. 